\title{
PENGARUH DURASI SHOT PEENING TERHADAP STRUKTUR MIKRO DAN KEKERASAN PERMUKAAN PADA AISI 316L
}

\author{
Rizqi Ilmal Yaqin ${ }^{1}$, Priyo Tri Iswanto ${ }^{1}$, Bambang Hari Priyambodo ${ }^{1,2}$, Erich Umbu Kondi M. ${ }^{1}$ \\ ${ }^{1}$ Departemen Teknik Mesin dan Industri, Fakultas Teknik \\ Universitas Gadjah Mada \\ Jl. Grafika No.2, Yogyakarta, 55281 Indonesia \\ ${ }^{2}$ Jurusan Teknik Mesin \\ Akademi Teknologi Warga Surakarta \\ J1. Raya Solo Baki Km. 2, Krawasan, Sukoharjo, Indonesia \\ Email : Ilmal.yaqin29@gmail.com
}

\begin{abstract}
Stainless steel 316L is widely used in medical applications. AISI 316L has good mechanical properties, good corrosion resistance and easy fabrication. On the other hand, $316 \mathrm{~L}$ should be upgraded its surface mechanical properties for implantable materials. One of the treatment used is shot peening. shot peening can increase surface hardness in the presence of micro structure changes. These changes are due to plastic deformation and residual stress. This study discusses the effect of shooting time duration of 2, 4, 10, 20, and 30 against the micro structure and surface hardness. The steel balls used are $0.6 \mathrm{~mm}$ in diameter and 40-50 HRC hardness with 8 bar pressure during shooting. the results of surface hardness on the duration of 2, 4, 10, 20 , and 30 minutes obtained respectively are $296.7 \mathrm{HV}, 380.8 \mathrm{HV}, 425.8 \mathrm{HV}, 445.0 \mathrm{HV}, 504.9$ $\mathrm{HV}$ and $523.1 \mathrm{HV}$ The surface hardness is increased due to structural changes on the surface and sub-surface of the shot peening material. The result of micro structure obtained is that with increasing duration of shot peening and the increasing of hardness value of surface hence grain size at sub surface that is smaller after treatment. Shot peening caused hardness of material $316 \mathrm{~L}$ stainless steel and made grain of microstructure sub layer.
\end{abstract}

Keywords : shot peening, Hardness, Structuremicro, AISI $316 \mathrm{~L}$

1. Pendahuluan

Baja tahan karat adalah salah satu bahan yang banyak digunakan dalam bidang industri dan biomedis karena memiliki sifat mekanis yang tinggi, ketahanan korosi yang baik dan harga yang relatif murah [1]. Salah satu jenis baja tahan karat yang banyak di pasaran adalah baja tahan karat austenitic. Baja tahan karat austenitik sendiri banyak diaplikasikan pada biomedis khususnya pada bahan implan. Bahan implan senidiri harus memiliki ketahanan korosi yang baik karena kontak langsung dengan tubuh. Cairan tubuh manusia banyak mengandung ion agresif yang menyebabkan korosi pada bahan implan. Selain tahan korosi, material implan harus memiliki sifat mekanis dan mudah dibentuk. Namun, baja tahan karat austenitik masih banyak terjadi kegagalan untuk aplikasi biomedis sendiri. Kegagalan baja austenitik banyak disebabkan korosi sumuran, ketahanan terhadap retak yang kurang, dan beberapa sifat mekanis yang kurang [2].

AISI 316L adalah salah satu bahan yang biasa digunakan dalam bahan implant. Bahan 316L memiliki sifat yang tahan korosi yang baik, biocompability [3], sifat mekanis yang baik, mudah di fabrikasi dan harga yang relatif murah daripada bahan yang lainnya.

Penelitian sebelumnya telah dilakakuan mengenai perbaikan sifat mekanis dan ketahanan korosi bahan 316L. Salah satu cara untuk memperbaiki bahan $316 \mathrm{~L}$ yaitu dengan perlakuan shot peening [4]. shot peening adalah salah satu proses perlakuan permukaan yang dapat meningkatkan sifat mekanik dan ketahanan korosi. Proses shot peening menggunakan bola baja yang ditembakan ke permukaan logam dengan kecepatan tinggi dan terkontrol. Proses shot 
peening menghasilkan deformasi plastis dan tegangan sisa tekan [5]. Shot peening dapat memberikan pengaruh pada peningkatan kekerasan disebabkan kerapatan ukuran butiran [6].

Kekerasan AISI 316L hasil shot peening telah diteliti oleh Azar dkk [7]. Penelitian menunjukkan bahwa adanya kekerasan permukaan meningkat seiring dengan bertambahnya waktu durasi shot peening. kekerasan permukaan yang didapat berkisar $400 \mathrm{HV}$ menjadi $500 \mathrm{HV}$ dengan durasi 5 sampai dengan 25 menit. Kekerasan meningkat disebabkan perubahan struktur mikro pada permukaan akibat deformasi plastis shot peening. Tebal deformasi dan jumlah butiran naik seiring dengan kenaikan durasi penembakan shot peening .

Bentuk struktur hasil shot peening juga telah diteliti oleh Liu dkk [8]. Penelitiannya tentang struktur nano dan permukaan lapisan hasil penembakan shot peening pada material Ti-6Al-4V menghasilkan adanya kenaikan ketebalan deformasi dan kenaikan butir seiring dengan kenaikan tekanan dan durasi penembakan shot peening. Hasil butiran dan kekasaran terbaik dengan variasi tekanan udara yang lebih kecil dan durasi penembakan yang lebih lama. Sedangkan hasil struktur mikro dari proses shot peening diperoleh pada Gambar 1.

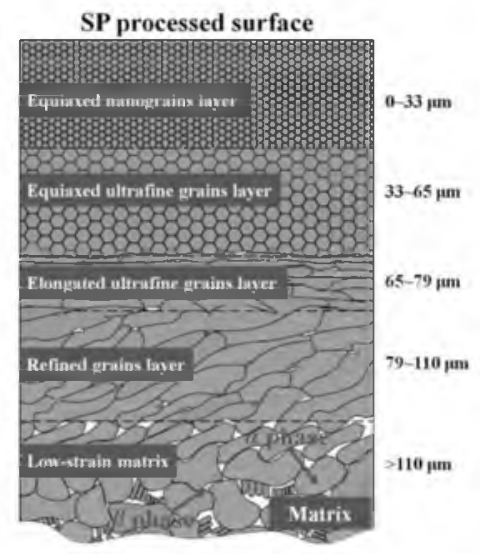

Gambar 1 Karakeristik Struktur hasil shot peening Ti-6Al-4V
Berdasarkan uraian diatas serta penelitian yang relevan dan pernah dilakukan, maka penelitian ini untuk mempelajari pengaruh perlakuan permukaan shot peening dengan variasi waktu $2,4,10$, 20 dan 30 menit terhadap struktur mikro dan kekerasan permukaannya. Material $316 \mathrm{~L}$ dengan perlakuan shot peening diharapkan dapat diaplikasikan pada biomedis.

2. Metode Penelitian

2.1 Preparasi Spesimen

Spesimen yang digunakan dalam penelitian ini yaitu stainless steel $316 \mathrm{~L}$ berbentuk plat dengan tebal $3 \mathrm{~mm}$ kemudian di potong secara manual dengan ukuran $2 \times 2$ $\mathrm{cm}$ masing masing sebanyak yang dibutuhkan. Selanjutnya permukaan dihaluskan dengan kertas amplas dibantu alat orbital sander dengan grade amplas $400,600,800,1000$, dan 2000. Setelah di haluskan dengan amplas, selanjutnya spesimen di finishing menggunakan autosol metal polish untuk menghilangkan goresan dan membuat permukaan spesimen lebih halus atau menyamakan kekasaran mulamula dan menkilap.

2.2 Perlakuan Shot peening

Spesimen yang sudah dihaluskan permukaannya di berikan perlakuan dengan shot peening dengan durasi waktu masingmasing spesimen yaitu 2,4,10,20, dan 30 menit dengan diameter steel ball $0,6 \mathrm{~mm}$. Alat shot peening terdiri dari kompresor krisbow 3HP 120L 10bar 380V, shot gun dengan diameter nozzle $5 \mathrm{~mm}$, selang karet penghubung container steel ball dengan shot gun, container steel ball, container box dan tempat proses shot peening.

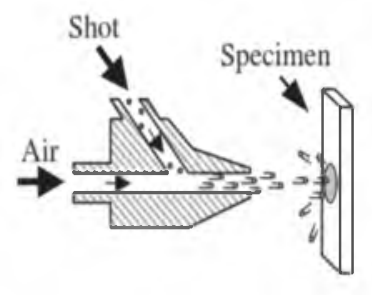

Gambar 2 Ilustrasi shot peening [9]

\subsection{Pengujian}

Pengujian kekerasan akan dilakukan dengan metode uji kekerasn mikro vicker dan menggunakan indentor berbentuk piramida yang terbuat intan dan dasarnya 
berbentuk bujur sangkar. Pengujian menggunakan standar ASTM E384 dengan pemberian beban 100 gram selama 10 detik. Data diambil sebanyak 3 kali setiap permukaannya.

Pengujian stuktur mikro dilakukan untuk mengetahui struktur mikro pada spesimen stainless steel yang terbentuk setelah dilakukan shot peening. Pemotongan dilakukan dalah arah lateral untuk mendapatkan penampang melintang, kemudian spesimen dihaluskan dengan kertas amplas 400, 800, 1200, 2000, dan 5000 . Proses selanjutnya spesimen dipoles dengan menggunakan autosol atau pengkilap logam dengan bantuan kain beludru sampai tanpa adanya goresan. Setelah itu dietsa menggunakan aqua regia etching reagent dengan komposisi $45 \mathrm{ml} \mathrm{HCl}$ dan $15 \mathrm{ml} \mathrm{HNO}_{3}$. Kemudian spesimen diamati dengan menggunakan foto mikroskop dan optilab yang dihubungkan dengan computer.

3. Hasil dan Pembahasan
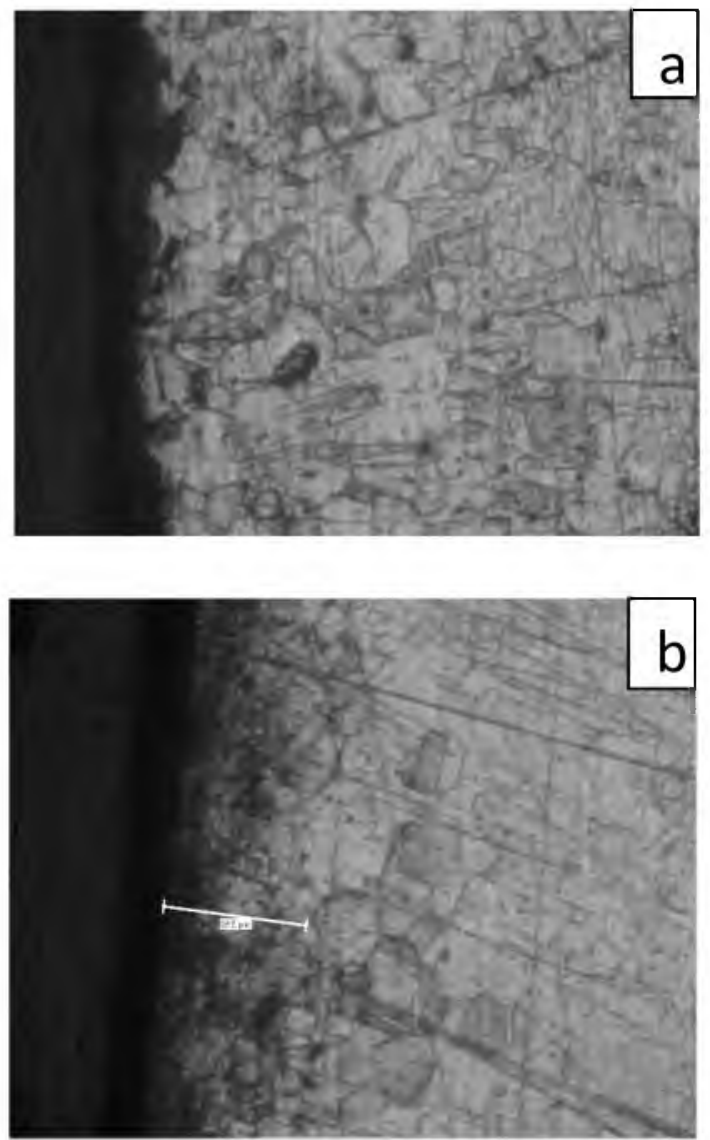

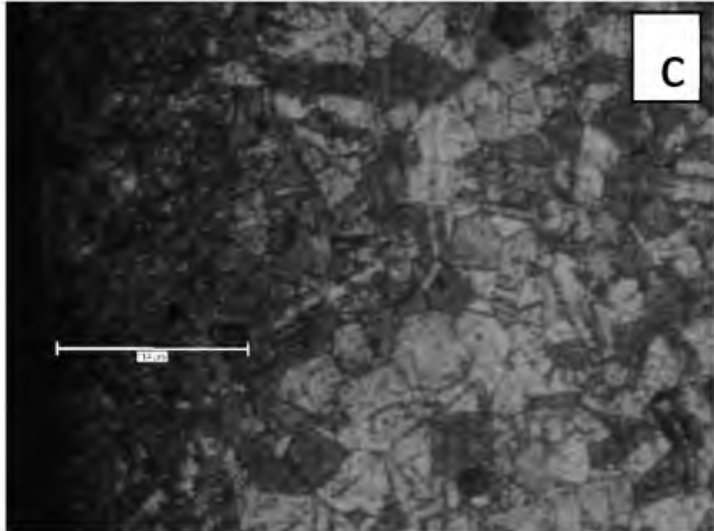

Gambar 1 Struktur mikro dengan perbesaran $100 \mathrm{x}$ a) raw material b) shot peening 4 menit dan c) shot peening 30 menit

\subsection{Struktur Mikro}

Pengujian strukur mikro dilakukan untuk mengetahui perubahan struktur mikro akibat proses hot peening. spesimen yang telah dietsa akan terlihat butiran butiran dengan batasnya. Gambar 3.a menunjukkan raw material tanpa perlakuan shot peening sedangkan Gambar 3.b menunjukkan struktur mikro pada spesimen dengan adanya perlakuan shot peening durasi 4 menit dimana adanya pengecilan struktur mikro sampai kedalam sekitar $88,5 \mu \mathrm{m}$ dan Gambar 3.b menunjukkan struktur mikro dengan adanya perlakuan shot peening durasi 30 menit dimana adanya pengaruh shot peening dengan kedalaman sekitar $114 \mu \mathrm{m}$. berdasarkan hasil tersebut dapat diduga bahwa kedalaman struktur mikro sangat tergantung dari pengaruh durasi shot peening. semakin lama durasi shot peening maka kedalaman penghalusan batas butir akan semakn dalam.

Berdasarkan hasil struktur mikro tersebut penghalusan butiran disebabkan adanya deformasi platis dari tumbukan bola baja. Perbedaan ukuran butiran struktur mikro akan terlihat pada daerah permukaan dan sub permukaan [10].

\subsection{Kekerasan Permukaan}

Pengujian dilakukan dengan metode vickers dengan perbandingan nilai durasi shot peening pda waktu $2,4,10,20$, dan 30 menit. Hasil pengujian kekerasan diambil rata-rata dari 3 kali pengujian 
kekerasan dan disajikan dalam grafik Gambar 4.

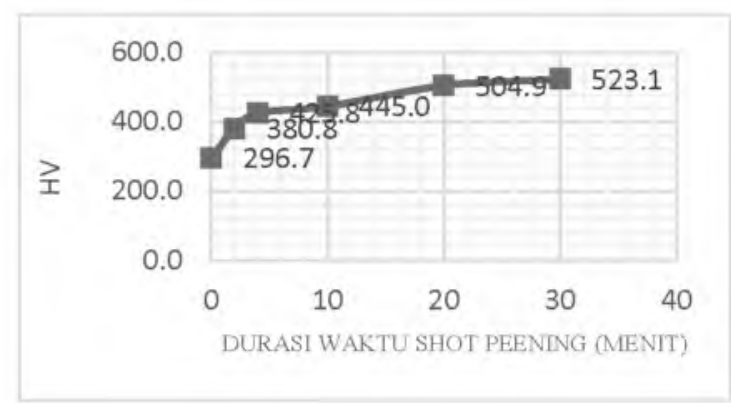

Gambar 4 Grafik kekerasan permukaan shot peening $316 \mathrm{~L}$

Gambar 4 menunjukakan bahwa adanya pengaruh perlakuan shot peening meningkatkan kekerasan pada permukaan. Nilai kekerasan tertinggi teletak pada durasi waktu 30 menit sebesar 523,1 HV. Nilai kekerasan tersebut menunjukkan bahwa adanya peningkatan kekerasan permukaan dengan penambahan durasi shot peening pada material 316L [7]. Kenaikan kekerasan permukaan sekitar $76 \%$ dari material $316 \mathrm{~L}$ yang belum diberi perlakuan shot peening. Kenaikan kekerasan pada material 316L disebabkan tingginya densitas dislokasi pada struktur mikro pada daerah sub layer hasil shot peening [11]. Dislokasi struktur pada permukaan hasil shot peening sendiri diakibatkan adanya tumbukan bola baja pada permukaan logam. Bola baja tersebut mengakibatkan dislokasi plastis pada permukaan. Semakin besar dislokasi plastis yang diberikan pada shot peening maka menyebabkan bertambahnya dislokasi di permukaan, Banyaknya dislokasi pada suatu daerah, dislokasi membentuk interaksi antar dislokasi terdekat lainnya. Interaksi antar dislokasi yang tinggi inilah yang menyebabkan kerapatan dislokasi terutama pada batas butir. Berdasarkan itu, butiran akan semakin halus dan saling menghambat interaksi dislokasinya. Hal tersebut menimbulkan efek pengerasan regangan atau yang sering disebut dengan strain hardening.

Berdasarkan grafik Gambar 4 menunjukkan nilai kekerasan permukaan optimum berda pada durasi 2 menit. perubahan yang signifikan dengan material yang belum diberi shot peening. Peningkatan tersebut sebesar $38 \%$. Setelah perlakuan shot peening 2 menit perubahan kekerasan permukaan spesimen tidak terlalu signifikan, hal ini terjadi disebabkan spesimen sudah terjadi pengerasan regangan pada permukaan. Berdasarkan penelitian digunakan diameter bola baja dan tekanan yang konstan. Bola baja dan tekanan yang konstan saat proses shot peening menyebabkan ketidakmampuan material 316L menghasilkan deformasi plastis yang sama besar pada permukaan saat material belum dilakukan perlakuan shot peening [12].

\section{Kesimpulan}

Shot peening dapat membuat kekerasan permukaan meningkat dan membuat memperhalus butiran pada sub permukaan dari material shot peening. semakin lama durasi shot pening struktur mikro yang di hasilkan sub lapisan permukaan akan semakin meningkat pengaruh ke dalam material. pengaruh shot peening paling optimum berada pada durasi 2 menit sebesar 380,8 HV sedangkan kekerasan paling keras paling maksimum berada pada 30 menit sebesar 523,1 HV. Struktur mikro pengaruh shot peening akan semakin dalam pengaruhnya seiring dengan bertambahnya durasi shot peening.

\section{Saran}

Adanya metode untuk menyaring bola baja yang sudah aus.

\section{Ucapan Terima kasih}

Penulis mengucapkan terima kasih kepada laboratorium bahan teknik departemen teknik mesin dan industri UGM yang telah memfasilitasi penulis dalam perlakuan shot peening dan pengujiannya terhadap penelitian ini.

\section{DAFTAR PUSTAKA}

[1] Ahmed, A. A., Mhaede, M., Basha, M, Wollmann, M., Wagner, L., 2014, Effect of surface and bulk plastic deformations on the corrosion resistance and corrosion fatigue performance of AISI 316L. Journal Surface \& Coatings Technology 259 
[2] Xu, S. X.Q.Wu, E.H, Han,W, Katada,Ke, 2008, Effect of oxidation behavior on the corrosion fatigue crack initiation and propagation of 316LN austenitic stainless steel in high temperature water, Mater. Sci. Eng. A 490 16-25.

[3] Arifvianto, B., Suyitno, Mahardika, M., Dewo, P., Iswanto, P. T., Salim, U. A. , 2011, Effect of surface mechanical attrition treatment (SMAT) on microhardness, surface roughness and wettability of AISI 316L. Materials Chemistry and Physics, Vol. 125, 418-426.

[4] Suyitno, dkk .,2012,. Effect of cold working and sandblasting on the microhardness, tensile strength and corrosion resistance of AISI $316 \mathrm{~L}$ stainless steel. International Journal of Minerals, Metallurgy, and Materials Vol.19 issue 12.

[5] Benedetti, M., Fontanari, B. Winiarski, P.J. Withers, M. Allahkarami, J.C. Hanan., 2015, Fatigue Behavior of Shot Peened Notched Specimens: Effect of The Residual Stress Field Ahead of The Notch Root, Procedia Engineering 109, pp. 80-88, Elsevier.

[6] Zhan, K., Jiang, C. H., Wu, X. Y. and $\mathrm{Ji}, \quad$ V., 2012, Surface Layer Characteristics of S30432 Austenite Stainless Steel after Shot Peening, Materials Transactions, Vol. 53, No. 5, pp. 1002-1006, Elsevier.
[7] Azar, V., Hashemi B., Yazdi, Mahboobeh Rezaee. , 2010, The effect of shoot peening on fatigue and corrosion behavior of $316 \mathrm{~L}$ stainless steel in Ringer's Solution. Journal Surface \& Coatings Technology 204,354-3551.

[8] Liu, Y.G., Li, M.Q., Liu, H.J. ,2017, Nanostructure and surface roughness in the processed surface layer of Ti$6 \mathrm{Al}-4 \mathrm{~V}$ via shot peening. Materials Characterization, Vol. 123, pp 83-90.

[9] Umemoto, M., ,2003, Nanocrystallization of Steels by Severe Plastic Deformation, Materials Transactions, The Japan Institute of Metals, Vol. 44, No.10, pp. 19001911.

[10] Liu, Y.G., Li, M.Q., Liu, H.J. ,2017, Nanostructure and surface roughness in the processed surface layer of Ti$6 \mathrm{Al}-4 \mathrm{~V}$ via shot peening. Materials Characterization, Vol. 123, pp 83-90.

[11] Jiang, C Q., and Xu, Z., 2014, Residual Stress Relaxation of ShotPeened Deformation Surface Layer on Duplex Stainless Steel Under Applied Loading, JMEPEG, pp. 408-412, Elsevier

[12] Wibowo, T. N., Iswanto, P. T., Priyambodo, B. H., Amin, N., 2016, Pengaruh Variasi Waktu Shot Peening terhadap Struktur Mikro dan Kekerasan Permukaan Pada Material Implan Aisi 304, Jurnal ROTOR, No.2, $\quad$ pp 